\title{
Quantitative characterization of volume of cavities in hydrodynamic cavitation device using computational fluid dynamics
}

\section{Caracterização quantitativa do volume de cavidades em um dispositivo de cavitação hidrodinâmica usando dinâmica de fluidos computacional}

\author{
Thiago Vinicius Ribeiro Soeira' \\ Guilherme Barbosa Lopes Junior" \\ Cristiano Poleto"II \\ Julio Cesar de Souza Inácio Gonçalvesı
}

\begin{abstract}
Hydrodynamic cavitation has been extensively studied for its potential to remove emerging pollutants. Despite the advance of the experimental studies involving this phenomenon, computational studies that evaluate the influence of the geometry of the cavitation devices on the flow parameters are still necessary. The purpose of this article was to evaluate the influence of the change in the geometry of a Venturi device on the volume of cavities formed in its divergent section using Computational Fluid Dynamics (CFD). The geometric parameters modified in the Venturi were: the diffuser angle and the relation between the height and the width of the throat $(\mathrm{h} / \mathrm{w})$. The volume of cavities is an important parameter because it influences the cavitation intensity. A cavitational bench system was constructed in order to obtain input data for simulation. The results showed that the increase in the diffuser angle from $6.5^{\circ}$ to $18.5^{\circ}$ gradually reduced the volume of cavities from $93 \mathrm{~mm}^{3}$ to $10 \mathrm{~mm}^{3}$. Between the relations $\mathrm{h} / \mathrm{w}=0.05$ and $\mathrm{h} / \mathrm{w}=0.45$ was observed the formation of cavities between $106 \mathrm{~mm}^{3}$ and $77 \mathrm{~mm}^{3}$, however between $\mathrm{h} / \mathrm{w}=0.45$ and $\mathrm{h} / \mathrm{w}=1.0$ there was the formation of $213 \mathrm{~mm}^{3}$. Therefore, Venturi's with diffuser angle less than $6.5^{\circ}$ and relation $\mathrm{h} / \mathrm{w}$ greater than 0.45 produce greater volume of cavities. The greater volume of cavities will not necessarily produce greater cavitational intensity, since cavitation clouds can be formed and reduce the implosion intensity of the cavitation bubbles.
\end{abstract}

Keywords: Advanced oxidation process; Hydrodynamic cavitation; Orifice plate.

\section{Resumo}

A cavitação hidrodinâmica tem sido amplamente estudada por seu potencial em remover poluentes emergentes. Apesar do avanço dos estudos experimentais envolvendo este fenômeno, ainda são necessários estudos computacionais que avaliem a influência da geometria dos dispositivos de cavitação nos parâmetros

'Federal University of Triângulo Mineiro, Uberaba, MG, Brasil - tvribeiro88@hotmail.com.

"Federal University of Pernambuco, Recife, PE, Brasil - lopesjunior.gb@gmail.com.

I'Federal University of Rio Grande do Sul, Porto Alegre, RS, Brasil - cristiano.poleto@ufrgs.

IVFederal University of Triângulo Mineiro, Uberaba, MG, Brasil - julio.goncalves@uftm.edu.br. 
de escoamento. O objetivo deste artigo foi avaliar, por meio da Dinâmica de Fluidos Computacional (CFD), a influência da mudança da geometria de um dispositivo de Venturi sobre o volume de cavidades formadas em sua seção divergente. Os parâmetros geométricos modificados no Venturi foram: o ângulo divergente e a relação entre a altura e a largura da garganta $(\mathrm{h} / \mathrm{w})$. O volume das cavidades é um parâmetro importante porque influencia a intensidade da cavitação. Um sistema de bancada cavitacional foi construído a fim de obter dados de entrada para simulação. Os resultados mostraram que o aumento do ângulo divergente de $6,5^{\circ}$ para $18,5^{\circ}$ reduziu gradativamente o volume das cavidades de $93 \mathrm{~mm}^{3}$ para $10 \mathrm{~mm}^{3}$. Entre as relações $\mathrm{h} / \mathrm{w}=0,05 \mathrm{e}$ $\mathrm{h} / \mathrm{w}=0,45$ observou-se a formação de cavidades entre $106 \mathrm{~mm}^{3}$ e $77 \mathrm{~mm}^{3}$, porém entre $\mathrm{h} / \mathrm{w}=0,45 \mathrm{e} \mathrm{h} / \mathrm{w}=$ 1,0 ocorreu a formação de $213 \mathrm{~mm}^{3}$. Portanto, Venturi's com ângulo divergente menor que $6,5^{\circ}$ e relação $\mathrm{h} / \mathrm{w}$ maior que 0,45 produzem maior volume de cavidades. $O$ maior volume de cavidades não necessariamente produzirá maior intensidade cavitacional, uma vez que nuvens de cavitação podem se formar e reduzir a intensidade de implosão das bolhas de cavitação.

Palavras-Chave: Processo de oxidação avançado; Cavitação hidrodinâmica; Placa de orifício. 


\section{Introduction}

The hydrodynamic cavitation $(\mathrm{HC})$ is occurred when fluid is forced through a physical constriction, provided by the orifice plate, Venturi tube or partially closed valve devices. When the pressure in the constriction decays below the liquid's vapor pressure, bubbles (cavities) begin to form. Downstream the constriction, the pressure recovers and the bubbles collapse, releasing high concentration of energy (pressures between 100 and $400 \mathrm{MPa}$ and local temperatures between 10,000 and 14,000 K) (PAWAR et al., 2017).

The HC phenomenon has been applied in numerous applications of sanitary and environmental engineering (involving physical-chemical processes), from water treatment (DULAR et al., 2016; BAGAL; GOGATE, 2014), wastewater containing pesticides (PATIL et al., 2014), drugs dissolved in water (THANEKAR et al., 2018; ZUPANC et al., 2013), effluent from tannery waste (SAXENA et al., 2018), effluent from soft drink industry (ALVES et al., 2019), to dye removal (RAJORIYA et al., 2017; RAJORIYA et al., 2018) and algae removal (BATISTA et al., 2017). In production processes there are reports over the use of $\mathrm{HC}$ ranging from the synthesis of biodiesel (MADDIKERI et al., 2014), pre-treatment of biomass (HILARES et al., 2017) to the production of nanoemulsion (CARPENTER et al., 2017).

Despite significant efforts in experimental research involving the cavitation dynamics, the characterization of parameters that are influenced by the geometry of the devices is still necessary. For this reason, the experimental studies are being developed together with the numerical studies due to the control of the boundary conditions and the manipulation of the geometry.

Li et al. (2017) investigated the relationship between cavitation and Venturi tube geometry by experimentation and simulation. The simulations allowed the authors to establish the main design parameters that are influential in the cavitation behavior. After identifying the critical geometric parameters, energy consumption and cavitation behavior were investigated by testing six Venturi tubes with different variations in their geometries.

Simpson and Ranade (2018b) used Computational Fluid Dynamics (CFD) to simulate cavitational flow through an orifice plate and correlate the results with other scientific studies. This work adopted the Eulerian-Eulerian approach with supplementary Lagrangian 
calculations in order to understand the individual bubbles trajectories. In addition, pressure gradients, velocity, turbulence, and volume fraction of the cavities were also analyzed and discussed.

Kuldeep and Saharan (2016) studied the HC phenomenon in slit, circular and elliptic Venturi devices, orifice plate with multiple holes and single hole, by modifying geometric and operational parameters. CFD simulations were carried out to investigate which of these devices would have the best cavitational effect.

Moholkar and Pandit (2001) present the bubble flow dynamics in HC considering the interactions between bubble-bubble and bubble-flow. The simulations were conducted to investigate the effect of outlet pressure (recovery) parameters, the relationship between the length and throat area, initial bubble fraction in the flow and initial bubble size.

Kumar et al. (2012) coupled the continuous mixing model to the limited diffusion model to study the cavitation flow dynamic behavior downstream an orifice plate. This model considers the interactions between bubble-bubble and bubble-flow, in addition to heat transfer and solvent vapor transport through the cavities along radial motion. The results of this study are presented in flow regime maps that identify a variety types of bubble behavior, becoming helpful in the $\mathrm{HC}$ device optimization for a particular chemical or physical process.

Pawar et al. (2017) compared cavitational intensity (sonochemistry effect) produced in Venturi devices and orifice plate. In addition to the experimental studies, the authors conducted CFD analysis with single-phase simulations applying the single bubble model to simulate bubble dynamics. According to the authors, most of the models describing the dynamics of cavitation bubbles were developed considering the radial motion of a single bubble, whereas real cavitation phenomena occurring in $\mathrm{HC}$ devices promote fields with millions of bubbles (clouds) interacting strongly. Therefore, that is one of the reasons why device's modeling and optimization become so challenging and this consideration can significantly modify cavitation's intensity predicted by models of single bubble. Furthermore, the cavitation bubbles interactions can lead to asymmetrical oscillations and collapse, altering the geometric sphericity of the bubbles. 
In order to broaden understanding of the $\mathrm{HC}$ phenomenon, mainly on the formation of bubbles, this work proposes quantitative characterization of the volume of cavities in the slit Venturi device from changes in its geometry, using the multiphase CFD models for the simulations. Thus, the diffuser angle and the relation between the height and width of the throat $(\mathrm{h} / \mathrm{w})$ will be changed in the geometry of the device.

\section{Material and methods}

Experimental and computational studies were developed in this work. The experimental studies were conducted only to obtain physical parameters (pressures and mean flow), which were used as input data in the computational model.

\subsection{Experimental System}

The cavitational system (Figure 1) was composed of a $200 \mathrm{~mm}$ diameter tank with a volumetric capacity of approximately $0.009 \mathrm{~m}^{3}$, having pipes with a diameter of 25.4 and $38.1 \mathrm{~mm}$. A KSB Hydrobloc P100 pump $(745,7 \mathrm{~W})$ was used for promoting flow. Four flow control valves (V1, V2, V3 and V4) were positioned in the tank, downstream of the pump, downstream of the cavitation chamber (Venturi tube) and in the bypass line, respectively. In addition, pressure meters (P1 and P2) were connected upstream and downstream of the Venturi. To measure the upstream pressure, a PCT-400Ri + Full Gauge digital controller with a measuring range of $0-3.440 \mathrm{kPa}$ and $10 \mathrm{kPa}$ resolution was used. To measure the downstream pressure, a piezometer was used, providing the unit in $\mathrm{mH} 2 \mathrm{O}$, with $10^{-3} \mathrm{~m}$ resolution. In order to control the temperature of the system, a heat exchanger was used in the tank. 
Figure 1 - Scheme of the experimental system (without scale

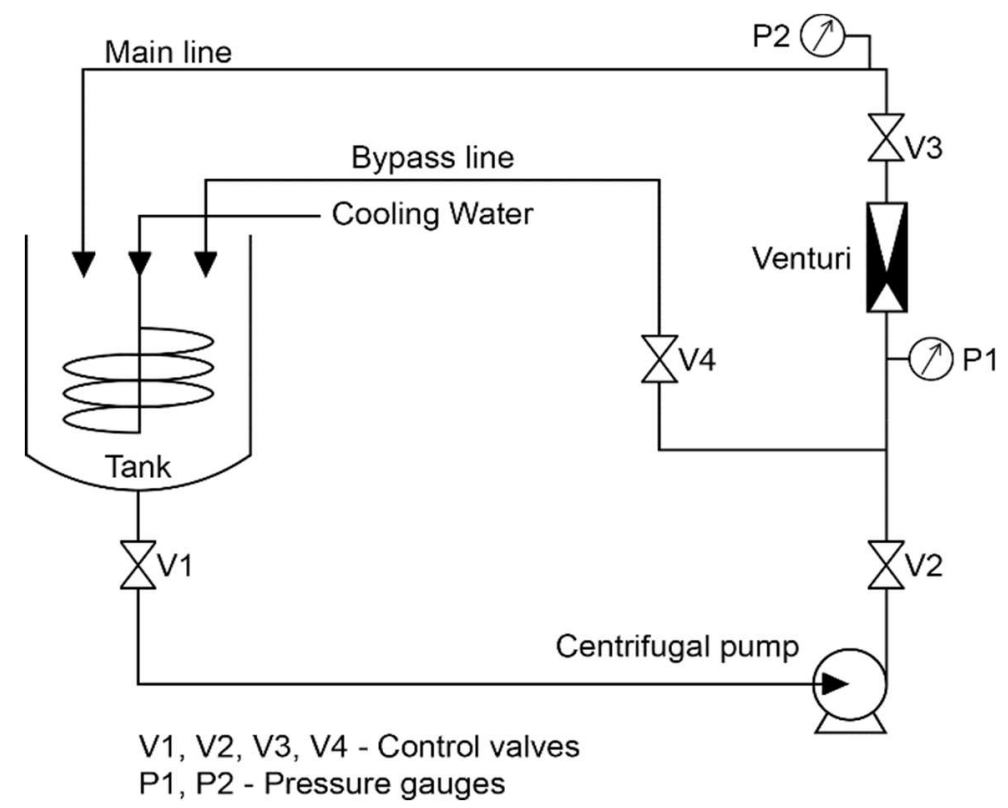

The HC device was made of transparent acrylic with slit Venturi tube structure. The Figure 2 shows the scheme of the device. The HC device consists mainly of three sections: the constriction, throat and diffusion sections. The device is $186.85 \mathrm{~mm}$ long, with $34.0 \mathrm{~mm}$ of constriction, $0.85 \mathrm{~mm}$ of throat and $152.0 \mathrm{~mm}$ of diffusion. The constriction angle is $22.5^{\circ}$, while the diffuser angle is $5.5^{\circ}$. The cross-sectional area of inlet and outlet is $900 \mathrm{~mm}^{2}(30.0$ $x 30.0 \mathrm{~mm})$, and the throat area is $6.97 \mathrm{~mm}^{2}(0.85 \times 8.2 \mathrm{~mm})$.

Figure 2 - Dimensions of the Venturi device (in millimeters)

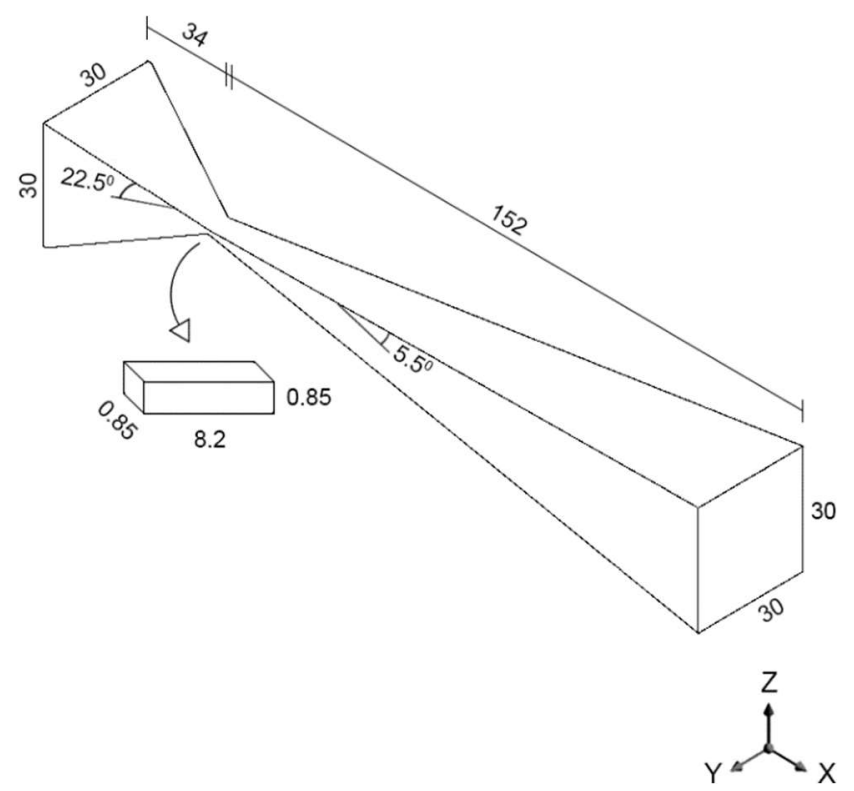




\subsection{Cavitation Experiments}

The experimental study was developed to investigate the phenomenon of hydrodynamic cavitation, in addition to collecting the physical parameters (inlet pressure P1, outlet pressure P2 and average flow) for the application and validation of the numerical models adopted. Table 1 presents the data set of mean pressures and flows obtained in the experimental study. It should be noted that the tests were performed using tap water. In total, five experiments were developed varying the inlet pressure, outlet pressure and average flow. The flow rate was measured in a properly calibrated orifice plate (flow coefficient $\mathrm{Cd}=0.70)$.

Table 1 - Experimental data

\begin{tabular}{ccc}
\hline $\begin{array}{c}\text { Inlet } \mathbf{P 1} \\
(\mathbf{k P a})\end{array}$ & $\begin{array}{c}\text { Pressure } \\
\text { Outlet } \mathbf{P 2} \\
\mathbf{( k P a )}\end{array}$ & $\begin{array}{c}\text { Average Flow } \\
\text { Experimental } \\
\left(\mathbf{m}^{3} \cdot \mathbf{s}^{-1}\right)\end{array}$ \\
\hline 200 & 5.9 & 0.00016 \\
270 & 6.1 & 0.00019 \\
350 & 6.2 & 0.00021 \\
420 & 6.3 & 0.00021 \\
540 & 6.6 & 0.00023 \\
\hline
\end{tabular}

\section{3 Governing Equations}

In order to comprehend the effects of Venturi's geometric characteristics on the formation of volume of cavities it was necessary to conduct a numerical treatment. The continuity and momentum equations are the flow governing equations.

Since the flow has two phases, water liquid and water vapor, the mixture model for the simulations is used (Equation 1).

$\frac{\partial}{\partial \mathrm{t}}\left(\rho_{\mathrm{m}}\right)+\nabla \times\left(\rho_{\mathrm{m}} \overrightarrow{\mathrm{V}}_{\mathrm{m}}\right)=0$

In which $\vec{V}_{\mathrm{m}}$ is the mean mass velocity:

$\overrightarrow{\mathrm{V}}_{\mathrm{m}}=\frac{\sum_{\mathrm{k}=1}^{\mathrm{n}} \alpha_{\mathrm{k}} \rho_{\mathrm{k}} \overrightarrow{\mathrm{V}}_{\mathrm{k}}}{\rho_{\mathrm{m}}}$

And $\rho_{m}$ is the density of the mixture: 


$$
\rho_{\mathrm{m}}=\sum_{\mathrm{k}=1}^{\mathrm{n}} \alpha_{\mathrm{k}} \rho_{\mathrm{k}}
$$

In which n expresses the number of phases and $\alpha_{\mathrm{k}}$ expresses the volume fraction from the $\mathrm{k}$ phase.

The sum of the momentum equations of each phase represents the global momentum equation expressed by:

$$
\frac{\partial}{\partial \mathrm{t}}\left(\rho_{\mathrm{m}} \overrightarrow{\mathrm{V}}_{\mathrm{m}}\right)+\nabla \times\left(\rho_{\mathrm{m}} \overrightarrow{\mathrm{V}}_{\mathrm{m}} \overrightarrow{\mathrm{V}}_{\mathrm{m}}\right)=-\nabla \mathrm{P}+\nabla \times\left[\left(\mu_{\mathrm{m}}+\mu_{\mathrm{t}}\right)\left(\nabla \overrightarrow{\mathrm{V}}_{\mathrm{m}}+\nabla \overrightarrow{\mathrm{V}}_{\mathrm{m}}^{\mathrm{T}}\right)\right]
$$

$$
\mu_{\mathrm{m}}=\sum_{\mathrm{k}=1}^{\mathrm{n}} \alpha_{\mathrm{k}} \mu_{\mathrm{k}}
$$

Using the Navier-Stokes equations with Reynolds averages it is possible to describe the turbulent flows. Realizable k- $\varepsilon$ model was adopted for modelling turbulence effect. According to Ashrafizadeh and Ghassemi (2015), this model is suitable for high speed multiphase fluids containing circulation and separation.

In cavitation, the mass transfer between the liquid and the vapor (condensation and evaporation) is controlled by the equation of vapor transport:

$$
\frac{\partial}{\partial_{\mathrm{t}}}\left(\alpha \rho_{\mathrm{v}}\right)+\nabla \times\left(\alpha \rho_{\mathrm{v}} \overrightarrow{\mathrm{V}}_{\mathrm{v}}\right)=\mathrm{R}_{\mathrm{e}}-\mathrm{R}_{\mathrm{c}}
$$


In which $\vec{V}_{v}, \rho_{v}, \alpha$, and $v$ are equivalent to the velocity of the vapor phase, the density of the vapor, the volume fraction of the vapor, and the phase of the vapor, respectively. $\mathrm{R}_{\mathrm{e}}$ and $R_{c}$ are the source terms of mass transfer linked to the vapor bubbles growth and collapse and are accountable for the liquid-vapor phase mass transfer in cavitation.

The Schnerr-Sauer model is employed to calculate the mass transfer from liquid phase to vapor phase. The source terms are:

$$
\text { When } \mathrm{P}_{\mathrm{v}} \geq \mathrm{P}_{1}
$$

$$
\mathrm{R}_{\mathrm{e}}=\frac{\rho_{\mathrm{v}} \rho_{\mathrm{l}}}{\rho} \alpha(1-\alpha) \frac{3}{\mathfrak{R}_{\mathrm{B}}} \sqrt{\frac{2}{3} \frac{\left(\mathrm{P}_{\mathrm{v}}-\mathrm{P}\right)}{\mathrm{P}_{\mathrm{l}}}}
$$

When $\mathrm{P}_{\mathrm{v}} \leq \mathrm{P}_{1}$

$$
\mathrm{R}_{\mathrm{c}}=\frac{\rho_{\mathrm{v}} \rho_{\mathrm{l}}}{\rho} \alpha(1-\alpha) \frac{3}{\Re_{\mathrm{B}}} \sqrt{\frac{2}{3} \frac{\left(\mathrm{P}-\mathrm{P}_{\mathrm{v}}\right)}{\mathrm{P}_{\mathrm{l}}}}
$$

In which $\rho_{\mathrm{l}}, \mathrm{P}$, and $\mathrm{P}_{\mathrm{v}}$ are the density of the liquid, local far-field pressure and vapor pressure, respectively. The Rayleigh-Plesset equation is used and depict the growth of a single vapor bubble in a liquid of radius $\mathfrak{R}_{\mathrm{B}}$ (ASHRAFIZADEH; GHASSEMI, 2015).

\section{4 Computational Modeling}

Since cavitation has unstable behavior, this phenomenon can only be well captured by simulations in three-dimensional models. In these types of models, the convergence and accuracy of numerical solutions can be improved compared to two- or one-dimensional models for a given device. (BRINKHORST et al., 2015).

Thus, a three-dimensional geometry of the Venturi device and a hexahedral mesh were built in the ANSYS DesignModeler and Meshing softwares, respectively, as shown in Figure 3. In order to minimize the influence of the numerical instability upstream and downstream of the device, the tube length at both ends was set equal to DN 30.

To guarantee mesh independence, the geometry was meshed with different mesh sizes and the test was validated as a function of the continuity equation (conservation of mass). The mesh independence was identified from 1.3 elements $/ \mathrm{mm}^{3}$ ( $\approx 154,000$ elements). 
Since the studies of this work promote geometric changes, and such changes cause small variations in the volume of the device, it was chosen to work with a density range of elements above the independent (between 1.7 and 7 elements $/ \mathrm{mm}^{3}$ ). In addition, the mesh quality was improved by applying the face sizing method with hard behavior to the entire structure. In the throat faces the size of the element was established $0.1 \mathrm{~mm}$ and, in the constriction, and diffusion faces it was $0.4 \mathrm{~mm}$.

Figure 3 - Zoom of the computational mesh in constriction, throat and diffusion regions

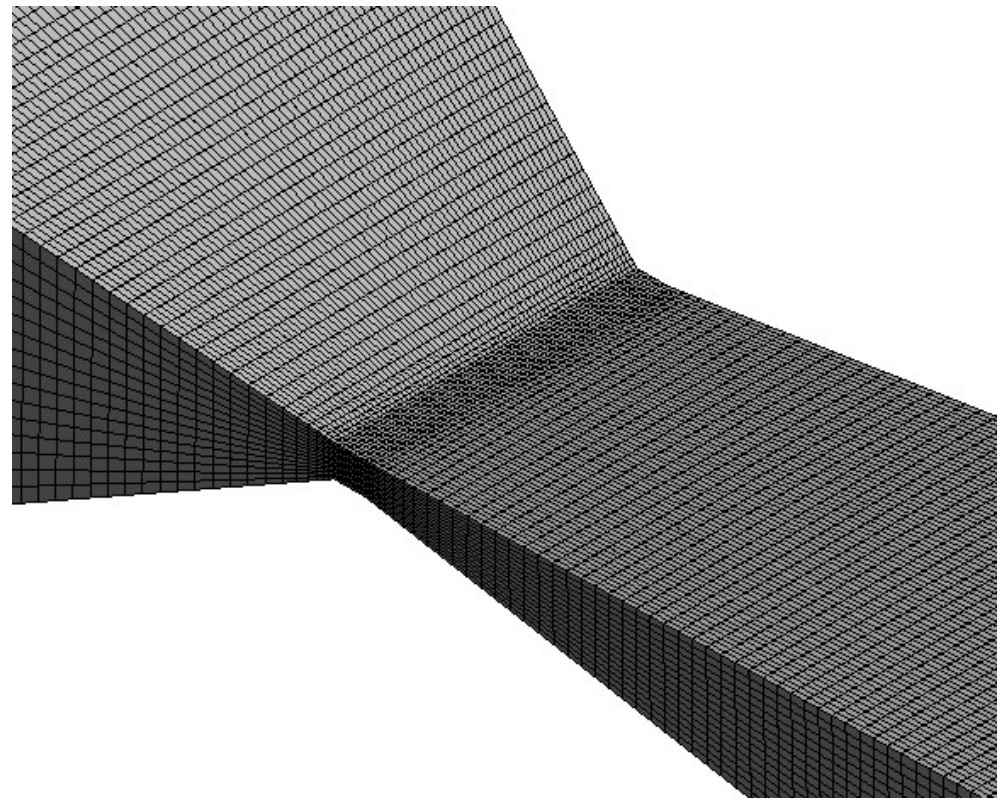

The ANSYS FLUENT software was chosen to promote the CFD simulations considering a 3D pressure-based solver and calculating the equations in steady-state conditions. The multiphase mixing model was adopted, with no slip velocity and no implicit body force. The Realizable k- $\varepsilon$ turbulence model with Enhanced Wall Treatment was used.

The density and viscosity of the liquid water were fixed constant at $998.2 \mathrm{~kg} / \mathrm{m}^{3}$ and $0.001003 \mathrm{~kg} / \mathrm{ms}$, respectively. Furthermore, the density and viscosity of water vapor were spotted on $0.5542 \mathrm{~kg} / \mathrm{m}^{3}$ and $0.0000134 \mathrm{~kg} / \mathrm{ms}$, respectively.

The Schnerr-Sauer cavitation model was adopted for the simulations, with vaporization pressure set constant at $3540 \mathrm{~Pa}$. The bubble number density was set at $10^{13}$. 
The control volume scheme was adopted to solve the equations of continuity and momentum. The SIMPLEC algorithm was applied to solve the pressure-velocity coupling. Spatial discretization for the gradient was the least squares cell based. For the pressure, the interpolation scheme PRESTO! was used. The second order upwind scheme was used to solve the momentum, turbulent kinetic energy and turbulent dissipation rate (scalar equations). Whereas for the volume fraction, the first order upwind scheme was applied. The Under-Relaxation Factors were kept in software default.

The simulations were operated with different pairs of inlet and outlet pressures (Table 1). In order to guarantee convergence and well accuracy of the simulated results, the following procedures were adopted:

1. Checking inlet and outlet flow rates at each iteration to ensure that both are equal (Principle of Mass Conservation).

2. The volume of water vapor formed was checked, at each iteration, to make sure they converge.

3. The iterations were developed until each of the residuals remained close to a constant value. For example, the continuity equation residual was set at $10^{-6}$.

4. In cases which residuals fluctuated significantly (in $\mathrm{h} / \mathrm{w}<0.01$, for example), the mesh was improved by the face sizing method, reducing the magnitude of the elements face for better convergence.

\subsection{Development of Scenarios}

Two sets of scenarios were designed to quantitatively investigate the volume of cavities formed in the slit Venturi considering the highest operating pressure.

In the first scenario, only the diffuser angle was changed, so that all other geometric parameters (the length of the constriction, throat and diffusion, the angle of the constriction, the height and width of the throat, and the inlet dimensions) of the device have remained unchanged. The physical quantities (outlet pressure and flow) remained constant in all simulations. In total, seventeen simulations were performed, changing the diffuser angle between $4.5^{\circ}$ and $30.5^{\circ}$. Figure 4 illustrates the influence of this angle on the device. 
Figure 4 - Slit Venturi with different diffuser angles (without scale

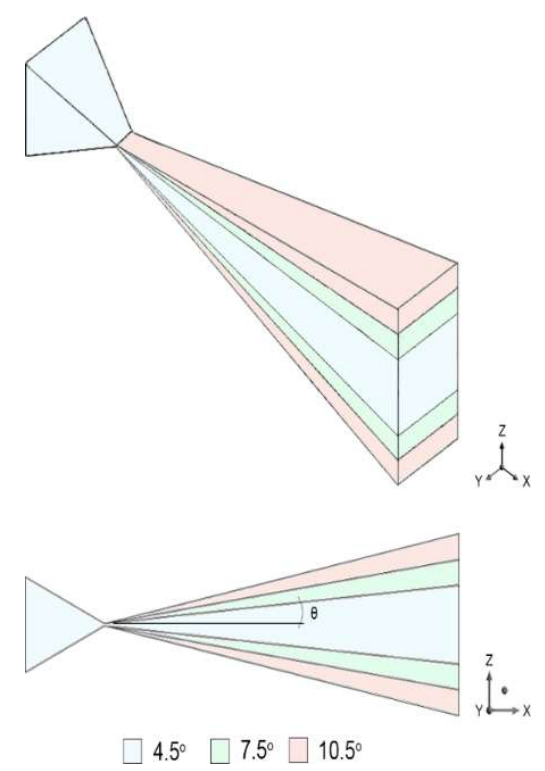

In the second scenario, the relation between the height and width of the throat was changed, so that all other geometric parameters (the length of the constriction, throat and diffusion, the constriction and diffusion angles, and the inlet dimensions) of the device have remained unchanged. As in the first scenario, the physical quantities remained constant in all simulations. Thirteen simulations were performed with $\mathrm{h} / \mathrm{w}$ ratio changes between 1 and 0.05. Figure 5 illustrates the influence of $h / w$ ratio on the device.

Figure 5 - Slit Venturi with different relations of the height and width of the throat (without scale)

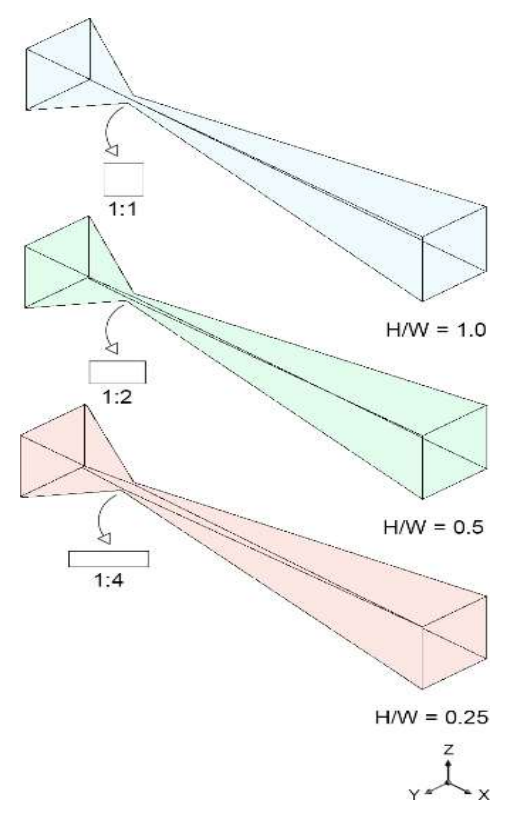




\section{Results and discussion}

\subsection{Effect of the pressure gradient}

The inlet pressure applied to cavitation chambers is a very important parameter that affects the cavitational condition, since cavity formation and cavitation intensity (magnitude of bubble collapse) depend essentially on the pressure difference across the reactor. The importance of the pressure gradient is demonstrated in several experimental studies, which confirm its influence on cavitational yield for the degradation of a variety of compounds (THANEKAR et al., 2018a), (THANEKAR et al., 2018b), (SAXENA et al., 2018), (BARIK; GOGATE, 2018), (BAGAL; GOGATE, 2014), (PATIL et al., 2014), (SAHARAN et al., 2013), (WANG; ZHANG, 2009).

In this work, the pressure values (P1 and P2) (Table 1) were adopted as input data for the simulations, while the flow rate was adopted as output data (response). For each set of inlet and outlet pressures, the flow rate, which was obtained computationally, was compared with the average flow from the experiments (Table 2). The flows had a deviation of $4 \%$ to $14 \%$. The largest variation was identified at the pressure of $350 \mathrm{kPa}$ and the lowest occurred at the pressure of $540 \mathrm{kPa}$.

The low inlet pressure in the device produces a small volume of cavities and this condition can lead to numerical errors, making it difficult to the convergence of the simulations, since in this work the multiphase model is adopted. This inconsistency can also be related both with experimental method errors and regarding the uncertainties of the measurements performed. According to Ashrafizadeh and Ghassemi (2015), the main sources of error in the numerical methods are related to models of turbulence and wall functions simplifications The wall functions are applied to avoid extreme mesh corrections; however, these models can cause failures, especially in flows that are limited by the walls, which may have occurred in the Venturi's throat of this study. 
Table 2 - Experimental and computational physical quantities

\begin{tabular}{ccccc}
\hline \multicolumn{2}{c}{ Pressure } & \multicolumn{2}{c}{ Flow rate } & Flow rate Deviation \\
$\begin{array}{c}\mathbf{P}_{\text {in }} \\
\mathbf{( k P a )}\end{array}$ & $\begin{array}{c}\mathbf{P} \text { out } \\
(\mathbf{k P a})\end{array}$ & $\begin{array}{c}\text { Experimental } \\
\left(\mathbf{m}^{\mathbf{3}} \cdot \mathbf{s}^{-\mathbf{1}}\right)\end{array}$ & $\begin{array}{c}\text { Computational } \\
\left(\mathbf{m}^{\mathbf{3}} \cdot \mathbf{s}^{-\mathbf{1}}\right)\end{array}$ & $\mathbf{( \% )}$ \\
\hline 200 & 5.9 & 0.00016 & 0.00015 & 6 \\
270 & 6.1 & 0.00019 & 0.00017 & 11 \\
350 & 6.2 & 0.00021 & 0.00018 & 14 \\
420 & 6.3 & 0.00021 & 0.00020 & 5 \\
540 & 6.6 & 0.00023 & 0.00022 & 4 \\
\hline
\end{tabular}

Nevertheless, the numerical results showed reliability compared to the experimental results and the simulations exhibited satisfactory prognosis of quantitative characterization of the phenomenon.

Figure 6 shows the pressure gradient effects along the front view of the device. The effect of the pressure gradient was analyzed for the operating pressures of $200 \mathrm{kPa}$ to 540 $\mathrm{kPa}$ and outlet pressures of $5.9 \mathrm{kPa}$ to $6.6 \mathrm{kPa}$, as indicated in Table 2 .

It is observed in Figure 6 that the pressure gradient expands with an increase in inlet pressure, extending the effective low-pressure zone. It is known that an increase in the pressure gradient may intensify bubble collapse due to higher turbulence tensions. Therefore, the pressure difference across the Venturi device is a crucial factor in cavitational intensity. It is also observed the decay of the pressure near the throat, giving rise to the formation of cavities. Then, after the effective low-pressure zone the pressure recovery occurs. The speed at which the pressure is recovered (recovery rate) is a fundamental parameter that influences the cavitational intensity. When cavity grows to an ideal size, its residence time in the low-pressure zone must be optimal before its collapse. In Venturi cases, the pressure recovery rate is influenced by the diffuser angle (as discussed in the next section). In cases which this rate is high, there will be boundary layer separation in the divergent section. The boundary layer separation may reduce the pressure recovered and increase the system's head loss. These observations are in agreement with the observations found in the literature (LI et al., 2017), (PAWAR et al., 2017), (KULDEEP; SAHARAN, 2016), (ASHRAFIZADEH; GHASSEMI, 2015). 
Figure 6 - Front view of the pressure contour for different operating pressures. The increase in operating pressure increases the pressure gradient in the device, extending the effective low-pressure zone.

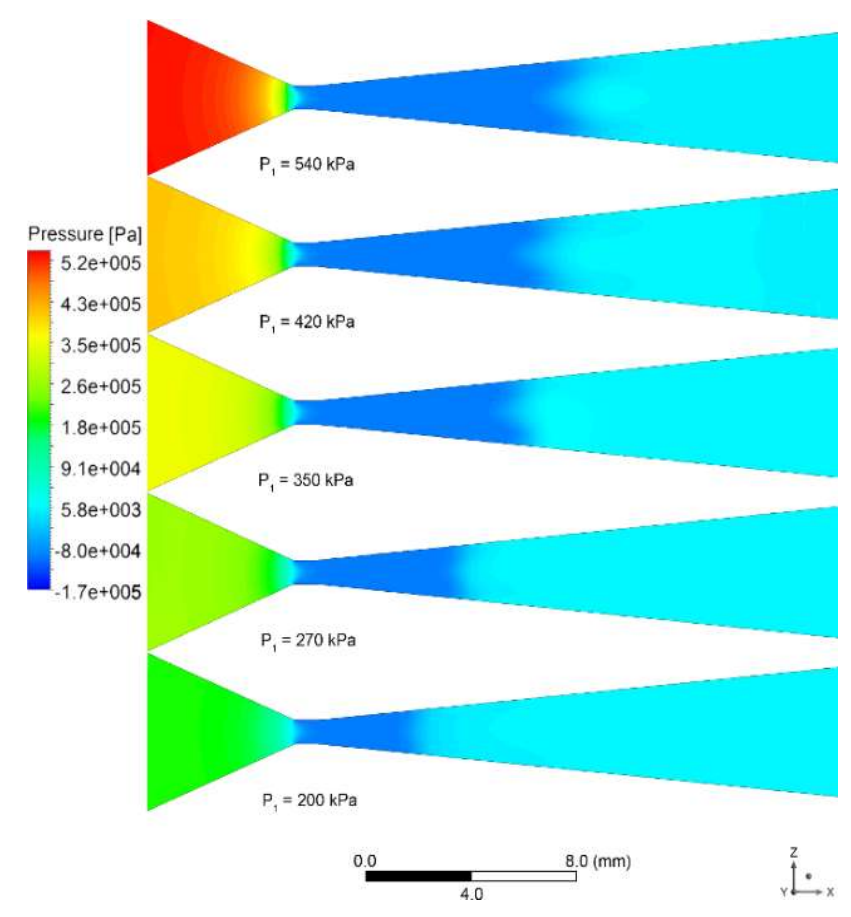

\subsection{Effect of the diffuser angle}

The diffusive angle of Venturis devices is a geometric parameter that influences cavitational activity. Therefore, it was studied and is illustrated in Figure 7.

Figure 7a shows three distinct regions. In the first region, composed by the smallest angles $\left(4.5^{\circ}\right.$ and $\left.6.5^{\circ}\right)$, a volume of cavities in the range of $93 \mathrm{~mm}^{3}$ is observed. In the second region, from the angle of $6.5^{\circ}$ to $18.5^{\circ}$, it is possible to notice a gradual decay of the volume of cavities, from approximately $93 \mathrm{~mm}^{3}$ to $10 \mathrm{~mm}^{3}$. In the third region, that is, from the angle of $18.5^{\circ}$ to $30.5^{\circ}$, the volume of cavities remains close to $10 \mathrm{~mm}^{3}$. This latter observation is also evidenced in the studies of Li et al. (2019), which report low volume of cavities formed in Venturi devices with diffuser angles above $19^{\circ}$. Therefore, it can be concluded that the increase in the Venturi's diffuser angle promotes the reduction of volume of cavities. 
Figure $7 \mathrm{~b}$ shows the fraction of volume of cavities of points I, II and III, located in regions 1, 2 and 3 of Figure 7a, respectively. From these illustrations, it is seen that the cavities are anchored near the throat section, growing and shrinking in the extent downstream of this point. Studies in this sense were also conducted by Ashrafizadeh and Ghassemi (2015), who concluded that increasing the diffuser angle the cavitation region becomes smaller. According to Simpson and Ranade (2018) and Xu et al. (2002), this phenomenon is not favorable, since this increase impairs the gradual recovery of pressure promoted by Venturi devices. When a Venturi has a larger diffuser angle, the recovery occurs abruptly with the separation of the flow from the walls and the appearance of a secondary rotational flow in the divergent section of the Venturi, resembling the flow behavior of the orifice plate.

According to Ashrafizadeh and Ghassemi (2015), the use of the $7^{\circ}$ diffuser angle in Venturi devices is recommended because of its minimal head loss. In works of Kuldeep and Saharan (2016) the diffuser angle between $5.5^{\circ}$ and $7.5^{\circ}$ promoted greater cavitational area for the slit, circular and elliptical Venturi devices. In addition, these authors state that small diffuser angles provide a slow recovery of pressure, allowing the cavities to reach the required maximum size before its collapse. It can be observed that these recommendations fall within region 1 of Figure 7a, reinforcing that smaller diffuser angles promote lower rates of pressure recovery and allow the formation of a greater cavitational region.

Continue... 
Figure 7 - Diffuser angle influence on the volume of cavities formed in slit Venturi and evidence of three distinct regions, region 1 , with approximately $93 \mathrm{~mm}^{3}$, region 2, with decay of $93 \mathrm{~mm}^{3}$ to $10 \mathrm{~mm}^{3}$ and region 3, with approximately $10 \mathrm{~mm}^{3}$ (a); the fraction of volume of cavities of points I, II and III, located in regions 1, 2 and 3, respectively (b).
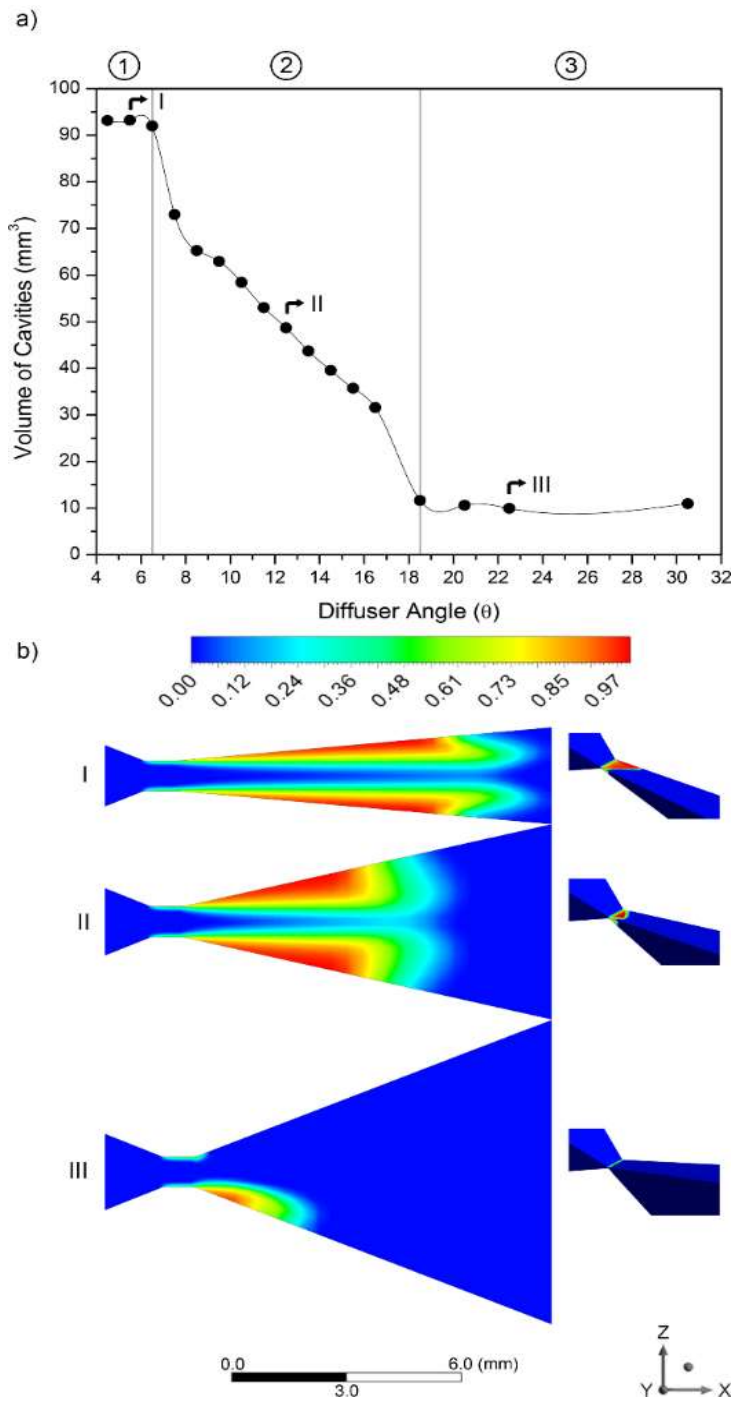

\subsection{Effect of the throat height and width}

The effect of geometric changes in throat height and width on cavity formation was also studied. Kuldeep and Saharan (2016) and Bashir et al. (2011) point out experimental studies by Moholkar, Kumar and Pandit (1999), who observed that the increase in the relation between the perimeter and the area of the throat increases the cavitational intensity. The relation $(\alpha)$ is given as: 
$\propto=\frac{\text { Throat's total perimeter }}{\text { Throat's total flow area }}$

The Equation 9 is used to aid in understanding the effects of throat height/width changes on cavity formation. As previously mentioned, this study promoted changes in the $\mathrm{h} / \mathrm{w}$ ratios so that the total flow area remained constant at $6,97 \mathrm{~mm}^{2}(0,85 \mathrm{~mm} \times 8,2 \mathrm{~mm})$ (Figure 2). Thus, it is evident that the smaller the $\mathrm{h} / \mathrm{w}$ ratio, the greater the perimeter of the throat and, consequently, the greater the value of $\alpha$.

Figure 8 shows the studied h/w ratios with their respective values of $\alpha$. Due to the logarithmic behavior of $\alpha$, Figure 8 can be divided into two distinct regions (regions 1 and 2). Between the relations $h / w=0.05$ and $h / w=0.45$ in region 1 , small modifications in $h / w$ provide large variations in the magnitude of $\alpha$, whereas in region 2 , between the relations $h / w=0.45$ and $h / w=1.0$ there is no evidence of large variations in the magnitude of $\alpha$. In this sense, it is possible to conclude that smaller $\mathrm{h} / \mathrm{w}$ ratios promote higher cavitational intensities

Figure 8 - Cavity intensity curve as a function of h/w ratios. Region 1, between h/w = 0.05 and $h / w=0.45$, large variations in the magnitude of $\alpha$. Region 2 , between $h / w=0.45$ and $\mathrm{h} / \mathrm{w}=1.0$, small variations in the magnitude of $\alpha$.

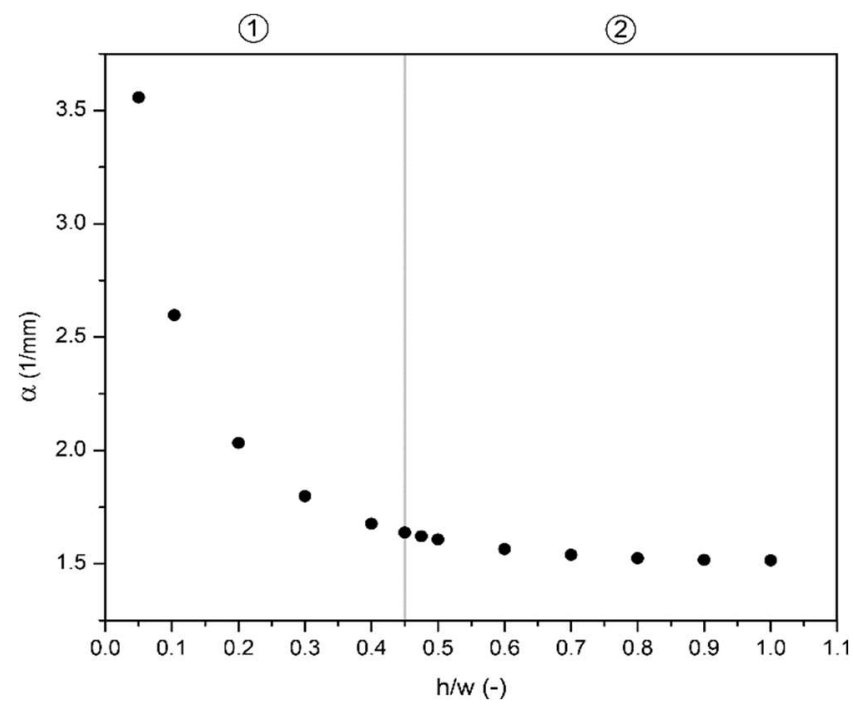

Figure 9 shows the influence of the relation between the height and width of the throat on the formation of volume of cavities. Figure 9a shows the curve of the volume of cavities formed from the $\mathrm{h} / \mathrm{w}$ changes and identifies the same regions of Figure 8 . In region 
1, the volume of cavities oscillated between 106 e $77 \mathrm{~mm}^{3}$, approximately. In region 2, the volume of cavities is close to $213 \mathrm{~mm}^{3}$. Therefore, there was a large increase in volume of cavities at ratios greater than $\mathrm{h} / \mathrm{w}=0.45$ (region 2). Comparing the two regions it is observed that the first region has approximately half the volume of cavities compared to the second one.

Moreover, Figure $9 \mathrm{~b}$ shows the fraction of volume of cavities of points I and II, located in regions 1 and 2 of Figure 9a, respectively. From these illustrations, it is seen that the cavities are better distributed in point II than in point I by virtue of the changes in h/w.

Considering the analysis of Figures 8 and 9, it is possible to notice that the region of greater cavitational intensity (region I) allowed the formation of smaller volume of cavities, which is a possible indication that lower $\mathrm{h} / \mathrm{w}$ ratios may hinder the formation of large cavity volumes (clouds). In addition, it is evident that the volume of cavities is not directly related to the cavitational intensity. In other words, the formation of large volume of cavities does not imply in high cavitational intensity.

Figure 9 - Influence of the throat height/width on the volume of cavities formed in Venturi and evidence of two distinct regions, region 1, with oscillation between 106 e 77 $\mathrm{mm}^{3}$, approximately, and region 2, with formation of approximately $213 \mathrm{~mm} 3(\mathrm{a})$; the fraction of volume of cavities of points I and II, located in regions 1 and 2, respectively (b).

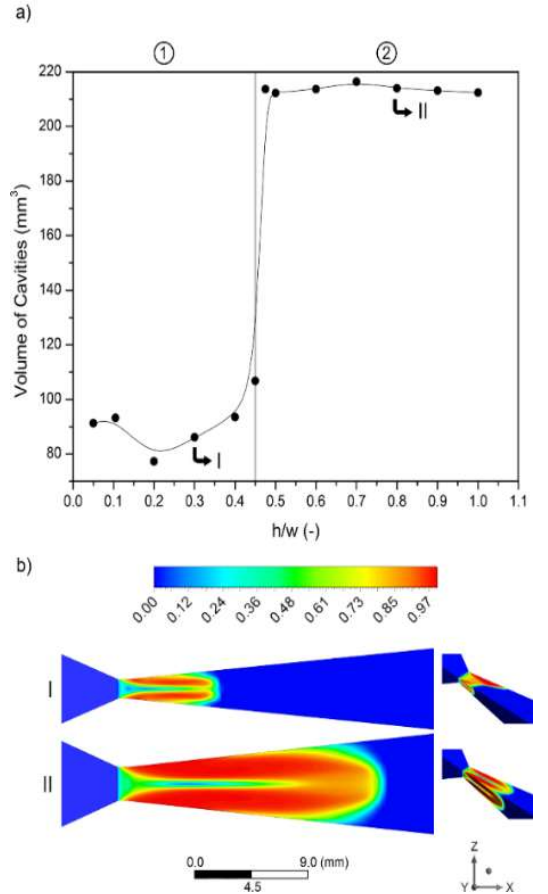


Pawar et al. (2017) also observed this result which indicate that the large amount of cavitation bubbles (clouds) can lead to a strong interaction and coalescence between them. This strong interaction causes the cavitation bubbles to lose their sphericity and reduce the intensity of their collapse, revealing an adverse effect on the formation of large volume of cavities (clouds). In terms of cavitational yield, lower numerical density of bubbles is desired for less interaction and coalescence between them, increasing the transient and symmetrical collapse intensity of the individual bubbles. The radical's recombination that could occur due to the vicinity of the bubbles would also tend to decrease, resulting in a more effective use of $\mathrm{HC}$ for oxidation and degradation of the compounds that are employed in this process.

\section{Conclusion}

This study characterized the presence of volume of cavities in the Venturi hydrodynamic cavitation device from changes in its geometry. Experimental studies were conducted for the collection of physical parameters and subsequent numerical validation of the results. Thus, the results of the simulations were in accordance with the experimental results, presenting a flow deviation of $4 \%$ to $14 \%$. The effect of the pressure gradient was evaluated and this was shown to be crucial for the cavitational yield, since its increase extends the low-pressure zone, intensifying the collapse of the bubbles due to greater turbulence tensions.

With the highest operating pressure two scenarios were studied: the first involving the diffuser angle and the second the throat height/width ratio. Some relevant conclusions are presented below: 1. A larger volume of cavities is produced when the diffuser angle of the diverging section is less than $6.5^{\circ}$; From $18.5^{\circ}$ the Venturi behaves as an orifice plate, i.e., the walls of the diverging section do not further influence the formation of cavities; 2 . Ratios h/w smaller than 0.45 produce a smaller volume of cavities and, according to the relation between the perimeter and the area of the throat, the greater will be $\alpha$ and the cavitational intensity; 3. Large volumes of cavities can generate cavitation clouds, reducing the implosion intensity of the bubbles and, consequently, the cavitational intensity. 


\section{Acknowledgments}

The authors are grateful to Fundação de Amparo à Pesquisa do Estado de Minas Gerais-FAPEMIG, to Coordenação de Aperfeiçoamento de Pessoal de Nível SuperiorCAPES and to Conselho Nacional de Desenvolvimento Científico e Tecnológico-CNPq, for their support.

\section{References}

ALVES, P. H. L.; SILVA, P. S. L.; FERREIRA, D. C.; GONÇALVES, J. C. S. I. COD removal from sucrose solution using hydrodynamic cavitation and hydrogen peroxide: a comparison between Venturi device and orifice plate. Revista Brasileira de Recursos Hídricos. 2019;24:18.

ANSYS, Inc. FLUENT Theory Guide. Ansys Inc. 2011.

ASHRAFIZADEH, S. M.; GHASSEMI, H. Experimental and numerical investigation on the performance of small-sized cavitating venturis. Flow Measurement and Instrumentation. 2015;42:6-15.

BAGAL, M. V.; GOGATE, P. R. Degradation of diclofenac sodium using combined processes based on hydrodynamic cavitation and heterogeneous photocatalysis. Ultrasonics Sonochemistry. 2014;21(3):1035-1043.

BARIK, A. J.; GOGATE, P. R. Hybrid treatment strategies for 2,4,6-trichlorophenol degradation based on combination of hydrodynamic cavitation and AOPs. Ultrasonics Sonochemistry. 2018;40:383-394.

BASHIR, T. A.; et al. The CFD driven optimisation of a modified venturi for cavitational activity. The Canadian Journal of Chemical Engineering. 2011;89(6):1366-1375.

BATISTA, M. D.; ANHÊ, A. C.B. M.; GONÇALVES, J. C. S. I. Use of Hydrodynamic Cavitation for Algae Removal: Effect on the Inactivation of Microalgae Belonging to Genus Scenedesmus. Water, Air, \& Soil Pollution. 2017;228(11):1-8.

BRINKHORST, S.; VON LAVANTE, E.; WENDT, G. Numerical investigation of cavitating Herschel Venturi-Tubes applied to liquid flow metering. Flow Measurement and Instrumentation. 2015;43:23-33.

CARPENTER, J.; GEORGE, S.; SAHARAN, V. K. Low pressure hydrodynamic cavitating device for producing highly stable oil in water emulsion: Effect of geometry and cavitation number. Chemical Engineering and Processing: Process Intensification. 2017;116:97-104. 
DULAR, M.; et al. Use of hydrodynamic cavitation in (waste)water treatment. Ultrasonics Sonochemistry. 2016;29:577-588.

HILARES, R. T.; et al. Hydrodynamic cavitation as an efficient pretreatment method for lignocellulosic biomass: A parametric study. Bioresource Technology. 2017;235:301-308.

KULDEEP, S. V. K. Computational study of different venturi and orifice type hydrodynamic cavitating devices. Journal of Hydrodynamics. 2016;28(2):293-305.

KUMAR, P.; KHANNA, S.; MOHOLKAR, V. S. Flow regime maps and optimization thereby of hydrodynamic cavitation reactors. Aiche Journal. 2012;58(12):3858-3866.

LI, M.; et al. Study of Venturi tube geometry on the hydrodynamic cavitation for the generation of microbubbles. Minerals Engineering. 2019;132:268-274.

$\mathrm{LI}, \mathrm{X}$, et al. Combined experimental and computational investigation of the cavitating flow in an orifice plate with special emphasis on surrogate-based optimization method. Journal of Mechanical Science and Technology. 2017;31(1):269-279.

MADDIKERI, G. L.; GOGATE, P. R.; PANDIT, A. B. Intensified synthesis of biodiesel using hydrodynamic cavitation reactors based on the interesterification of waste cooking oil. Fuel. 2014;137:285-292.

MOHOLKAR, V. S.; KUMAR, P. S.; SENTHIL, P.; PANDIT, A. B. Hydrodynamic cavitation for sonochemical effects. Ultrasonics Sonochemistry. 1999;6(1-2):53-65.

MOHOLKAR, V. S.; PANDIT, A. B. Numerical investigations in the behaviour of onedimensional bubbly flow in hydrodynamic cavitation. Chemical Engineering Science. 2001;56(4):1411-1418.

PATIL, P. N.; BOTE, S. D.; GOGATE, P.R. Degradation of imidacloprid using combined advanced oxidation processes based on hydrodynamic cavitation. Ultrasonics Sonochemistry. 2014;21(5):1770-1777.

PAWAR, S. K.; et al. Sonochemical effect induced by hydrodynamic cavitation: Comparison of venturi/orifice flow geometries. Aiche Journal. 2017;63(10):4705-4716.

RAJORIYA, S.; et al. Treatment of textile dyeing industry effluent using hydrodynamic cavitation in combination with advanced oxidation reagents. Journal of Hazardous Materials. 2018;344:1109-1115.

RAJORIYA, S.; BARGOLE, S.; SAHARAN, V. K. Degradation of reactive blue 13 using hydrodynamic cavitation: Effect of geometrical parameters and different oxidizing additives. Ultrasonics Sonochemistry. 2017;37:192-202.

SAHARAN, V. K. et al. Effect of geometry of hydrodynamically cavitating device on degradation of orange-G. Ultrasonics Sonochemistry. 2013;20(1):345-353. 
SARC, A. et al. The issue of cavitation number value in studies of water treatment by hydrodynamic cavitation. Ultrasonics Sonochemistry. 2017;34:51-59.

SAXENA, S.; SAHARAN, V. K.; GEORGE, S. Enhanced synergistic degradation efficiency using hybrid hydrodynamic cavitation for treatment of tannery waste effluent. Journal of Cleaner Production. 2018;198:1406-1421.

SIMPSON, A.; RANADE, V. V. Modeling hydrodynamic cavitation in venturi: influence of venturi configuration on inception and extent of cavitation. Aiche Journal, 2018a;65(1):421433.

SIMPSON, A.; RANADE, V. V. Modelling of hydrodynamic cavitation with orifice: Influence of different orifice designs. Chemical Engineering Research and Design. 2018b;136:698-711.

THANEKAR, P.; MURUGESAN, P.; GOGATE, P. R. Improvement in biological oxidation process for the removal of dichlorvos from aqueous solutions using pretreatment based on Hydrodynamic Cavitation. Journal of Water Process Engineering. 2018;23:20-26.

THANEKAR, P.; PANDA, M.; GOGATE, P. R. Degradation of carbamazepine using hydrodynamic cavitation combined with advanced oxidation processes. Ultrasonics Sonochemistry. 2018;40:567-576.

WANG, X.; ZHANG, Y. Degradation of alachlor in aqueous solution by using hydrodynamic cavitation. Journal of Hazardous Materials. 2009;161(1):202-207.

XU, C.; HEISTER, S. D.; FIELD, R. Modeling Cavitating Venturi Flows. Journal of Propulsion and Power. 2002;18(6):1227-1234.

ZUPANC, M.; et al. Removal of pharmaceuticals from wastewater by biological processes, hydrodynamic cavitation and UV treatment. Ultrasonics Sonochemistry. 2013;20(4):11041112. 